\title{
Direct oral anticoagulants for secondary prevention in patients with non-valvular atrial fibrillation
}

\author{
Luca Masotti, ${ }^{1}$ Mario Di Napoli, ${ }^{2}$ Walter Ageno, ${ }^{3}$ Davide Imberti, ${ }^{4}$ Cecilia Becattini, ${ }^{5}$ Maurizio Paciaroni,,${ }^{5}$ \\ Daniel Augustin Godoy, ${ }^{6}$ Roberto Cappelli, ${ }^{7}$ Giancarlo Landini, ${ }^{8}$ Grazia Panigada, ${ }^{9}$ Ido Iori, ${ }^{10}$ Domenico Prisco, ${ }^{11}$ \\ Giancarlo Agnelli ${ }^{5}$
}

${ }^{1}$ UO Medicina Interna, Ospedale di Cecina (LI), Italy; ${ }^{2}$ UOC Neurologia, Ospedale Generale San Camillo de' Lellis, Rieti, Italy; ${ }^{3}$ Dipartimento di Medicina Clinica, Università dell'Insubria, Varese, Italy; ${ }^{4} \mathrm{UO}$ Medicina Interna, Ospedale di Piacenza, Italy; ${ }^{5}$ Medicina Interna e Stroke Unit, Università degli studi di Perugia, Italy; ${ }^{6}$ Unidad de Cuidados Neurointensivos Sanatorio Pasteur and Unidad de Terapia Intensiva Hospital Interzonal de Agudos San Juan Bautista, Catamarca, Argentina; ${ }^{7}$ Centro Trombosi, Università degli Studi di Siena, Italy; ${ }^{8}$ UO Medicina Interna, Ospedale Santa Maria Nuova, Firenze, Italy; ${ }^{9} \mathrm{UO}$ Medicina Interna, Ospedale di Pescia (PT), Italy; ${ }^{10} \mathrm{UO}$ Medicina Interna, Ospedale Reggio Emilia, Italy; ${ }^{11}$ Dipartimento di Medicina Sperimentale e Clinica, Università degli Studi di Firenze, Italy

\begin{abstract}
The patients with non-valvular atrial fibrillation (NVAF), both permanent and paroxysmal, and history of previous transient ischemic attack (TIA) or stroke represent a category of patients at high risk of new embolic events, independently of the presence of other risk factors. In these patients, national and international guidelines recommend oral anticoagulants as first choice for antithrombotic prevention. Direct oral anticoagulants (DOACs) have been demonstrated to be not inferior to warfarin for many end points in NVAF patients in terms of efficacy and safety. The post hoc analysis in selected subgroups of patients enrolled in the three mega trials of phase III comparing DOACs (RE-LY,

Correspondence: Luca Masotti, UO Medicina Interna, Ospedale di Cecina, via Montanara, Località Ladronaia, 57023 Cecina (LI), Italy.

Tel.: +39.586.614212 - Fax: +39.586 .614218 .

E-mail: luca.masotti@tin.it

Key words: atrial fibrillation, warfarin, stroke, prophylaxis, dabigatran, rivaroxaban, apixaban.

Conflict of interests: the authors declare the following conflicts of interest: Dr Luca Masotti, Dr Mario Di Napoli, Dr Davide Imberti, Dr Maurizio Paciaroni, Dr Cecilia Becattini, Dr

ROCKET-AF and ARISTOTLE) with warfarin help to evaluate whether superiority and non-inferiority persist in these subgroups. Here, patients with NVAF and history of previous TIA/stroke receiving DOACs as secondary prevention are compared with patients with the same characteristics receiving warfarin. An analysis of these patients has been recently published (separately for each of three DOACs). This analysis shows that DOACs maintain their non-inferiority when compared with warfarin in secondary prevention, representing a real alternative in this context of patients at high risk for ischemic and bleeding events.
\end{abstract} Daniel Godoy, Dr.ssa Grazia Panigada, Dr Giancarlo Landini, Prof Roberto Cappelli: none.

Prof Walter Ageno: Advisory Boards promoted by Bayer Schering Pharma and BMS/Pfizer. He received honorarium as Speaker at Congresses promoted by Bayer Schering Pharma, BMS/Pfizer and Boheringer Ingelheim.

Dr Ido Iori: Advisory Boards promoted by Boehringer Ingelheim and Pfizer.

Prof Domenico Prisco received honorarium for Lectures and Advisory Boards from GSK, Bayer Schering Pharma and Daiichi Sankyo.

Prof Giancarlo Agnelli received honorarium for Lectures and Advisory Boards from GSK, Bayer Schering Pharma and Daiichi Sankyo.

Received for publication: 6 March 2013.

Revision received: 4 July 2013.

Accepted for publication: 29 August 2013.

This work is licensed under a Creative Commons Attribution NonCommercial 3.0 License (CC BY-NC 3.0).

CC Copyright L. Masotti et al., 2013

Licensee PAGEPress, Italy

Italian Journal of Medicine 2013; 7(s8):8-21

doi:10.4081/itjm.2013.s8.8

\section{Introduction}

Atrial fibrillation (AF) is the most common cardiac arrhythmia in the general population and in clinical practice. ${ }^{1-4}$ Its presence increases 2-7-fold the risk of ischemic stroke and systemic embolism compared to patients in sinus rhythm, showing a mean incidence of new embolic events of approximately $5 \%$ per year. ${ }^{5-8}$ The magnitude of AF embolic risk is influenced by the presence of additional prognostic factors: age over 65 years, congestive heart failure, blood hypertension, diabetes, history of previous transient ischemic attack (TIA) or stroke, history of vascular diseases, female sex. Their weight in predicting embolic risk has been codified in practical scales such as the $\mathrm{CHADS}_{2}$ and the most recently released $\mathrm{CHA}_{2} \mathrm{DS}_{2}$-VASC. These are well known and have been extensively validated in clinical practice. ${ }^{5} \mathrm{~A}$ history of a previous TIA or stroke is considered a par- 
ticularly important predictor of recurrent embolic events since its presence gives a score of 2 in the $\mathrm{CHADS}_{2}$ and it is equivalent to age over 75 years in $\mathrm{CHA}_{2} \mathrm{DS}_{2}$-VASC. ${ }^{5}$ In both scales, the presence of a score of 2 or over is indicative of subjects at high risk of stroke or systemic embolism ( $>4 \% /$ year if $\mathrm{CHADS}_{2}$ $\geq 2,>2.2 \% /$ year if $\mathrm{CHA}_{2} \mathrm{DS}_{2}-\mathrm{VASC} \geq 2$ ). Therefore, the history of a previous TIA or stroke itself identifies those subjects at high risk of embolism.

The most recent guidelines on the treatment and clinical management of patients with NVAF agree in recommending oral anticoagulants, either vitamin $\mathrm{K}$ antagonists (VKAs) or direct oral anticoagulants (DOACs), as the first choice of treatment in thromboembolic prevention in patients at high or moderate risk of stroke or systemic embolism. Despite the fact that patients at high risk of cerebral or systemic embolism represent a category with increased bleeding risk too, treatment with VKAs seem to provide the most net clinical benefit in patients with $\mathrm{CHADS}_{2}$ of 2 or over. ${ }^{9}$ The most recent guidelines suggest as a possible alternative the combination acetylsalicylic acid (ASA)/clopidogrel to oral anticoagulants in patients at low bleeding risk or ASA alone in patients at high bleeding risk when oral anticoagulants are contraindicated because of limitations or when not accepted by the patient. ${ }^{5-8,10}$ In patients at low embolic risk, no antithrombotic therapy is recommended. However, where the physicians are inclined to recommend antithrombotic prevention therapy, the guidelines suggest the use of ASA alone ${ }^{5-8,10}$ (Figure 1).

Vitamin K antagonists reduce the relative risk of stroke and systemic embolism by $64 \%$ (95\% confidence interval (95\% CI): 49-74\%) versus placebo with a number needed to treat (required number of patients treated to avoid an event, NNT) of 40 in primary prevention and 14 in secondary prevention and 39\% (95\% CI: $19-53 \%$ ) versus ASA. ${ }^{11}$ DOACs, direct thrombin inhibitors (dabigatran) and Factor Xa (rivaroxaban and apixaban) have been shown to be not inferior to warfarin in terms of efficacy and safety in the majority of the end points considered in three phase III randomized clinical trials (RCTs) (RE-LY for dabigatran, ROCKETAF for rivaroxaban, ARISTOTLE for apixaban). In particular, in the primary efficacy (combination of ischemic and hemorrhagic strokes and systemic embolism) and safety end point (major bleedings or, just for rivaroxaban, combination of major and non-major but clinically relevant bleedings). ${ }^{12-14}$ Higher doses of dabigatran (150 mg administered twice daily) and apixaban have also been shown to be superior to warfarin in the primary end point of efficacy, while rivaroxaban has been demonstrated to be superior only in the statistical analysis per protocol (on treatment) but not in the overall intention to treat analysis. ${ }^{12-14}$ However, it should be noted that rivaroxaban shows superiority on warfarin in the intention to treat analysis during treatment (HR 0.79 (95\% CI: 0.66-0.96); P for superiority $=0.02$ ), while it shows non-superiority in the intention to treat analysis after treatment discontinuation (HR 1.10 (95\% CI: 0.791.52); $\mathrm{P}$ for superiority $=0.58$ ). Dabigatran at a higher dose has also been demonstrated to be superior to warfarin in reducing the risk of ischemic strokes (relative risk (RR) 0.76, 95\% CI: 0.59-0.97). Overall, DOACs have shown a good safety profile, resulting non-inferior and, for many safety end points, also superior to warfarin with exception of inferiority on gastrointestinal bleedings for higher dose of dabigatran $(150 \mathrm{mg}$ twice/day) and rivaroxaban. However, it should be said that the post-marketing analysis by the Food and Drug Administration (FDA) has demonstrated that the risk of gastrointestinal bleeding is 3 -fold lower for dabigatran in comparison to warfarin in real life. ${ }^{15}$ Of utmost significance is the overall relative risk reduction (RRR) of $55 \%$ of intracranial bleedings associated with DOACs when compared to warfarin. ${ }^{16-18}$

The results of the three phase III RCTs on DOACs in NVAF have been described in detail and commented on in a previous article. ${ }^{19}$ The details of these RCTs are summarized in Tables 1-3.

The results of these phase III RCTs have already been accepted by the scientific community and DOACs are now included in the latest guidelines on clinical management of NVAF published by the most important international scientific Societies, such as the American College of Chest Physicians (ACCP) and the European Society of Cardiology (ESC). DOACs are recommended as the first choice for thromboembolic prevention in high risk (grade of recommendation and level of evidence IA) or moderate risk (IB recommendation ACCP, IIAa ESC) patients with NVAF, as are VKAs over which, however, these should be preferred. ${ }^{5,8}$

The combination of ASA plus clopidogrel significantly reduces the risk of thromboembolism when compared with ASA alone but it is not superior over ASA alone in reducing the all cause mortality rate or the combined end point all cause mortality plus morbidity, as shown by the ACTIVE-A study (Atrial Fibrillation Clopidogrel Trial With Irbesartan for Prevention of Vascular Events-Aspirin). Furthermore, this combination causes a significant increase in total bleedings over ASA alone ${ }^{20}$ with a rate of bleedings similar to that of VKAs and a reduction in terms of efficacy when compared to VKAs, as evident from the results of the ACTIVE-W study. ${ }^{21}$ ASA is considered the fourth choice of prevention therapy in patients with NVAF at high or moderate thromboembolic risk, as it reduces (not significantly) the relative risk of stroke compared with placebo by $19 \%$ (95\% CI: -1 to $35 \%) ., 5,8,11$

A practical flow chart on the most recent recommendations for antithrombotic prevention in NVAF is shown in Figure 1.5,8 


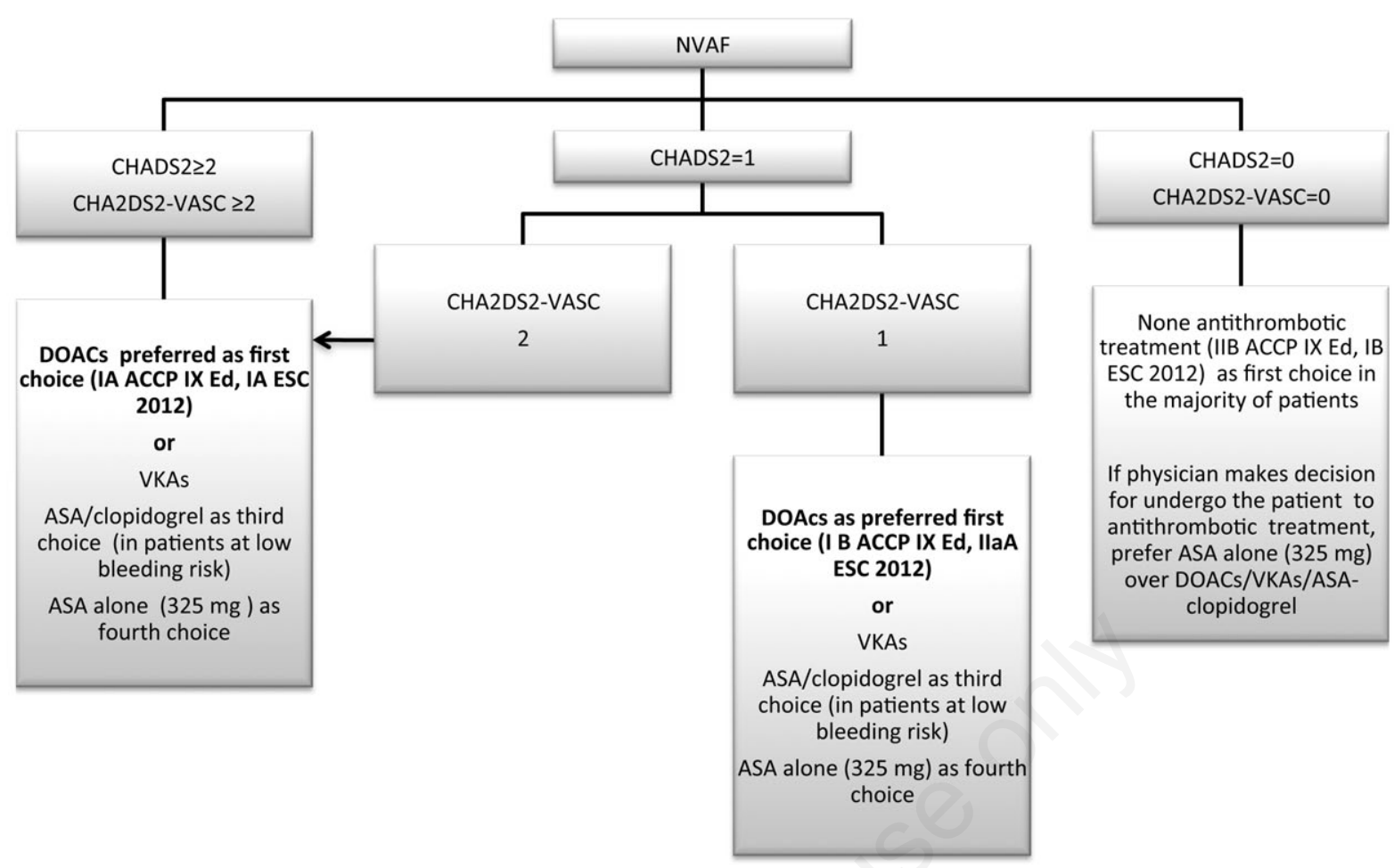

Figure 1. Summary of most recent guidelines on thromboembolic prevention in patients with non-valvular atrial fibrillation (NVAF).

\section{DOACs in secondary prevention: findings from phase III randomized controlled trials}

Post hoc analyses of selected subgroups of patients enrolled in the phase III RCTs on DOACs in NVAF have also been published. The analysis of the results related to patients with history of previous TIA/stroke enclosed in these trials (secondary prevention) is of great interest because of the related consequences in clinical practice. ${ }^{16-18}$ Patient cohorts with previous TIA/stroke enrolled in the three RCTs numbered: 1195 for the RE-LY $110 \mathrm{mg}, 1233$ for the RE-LY $150 \mathrm{mg}$, 3754 for the ROCKET-AF, 1694 for the ARISTOTLE studies, respectively, compared with 4819 (RE-LY 110), 4843 (RE-LY 150), 3377 (ROCKET-AF), 7426 (ARISTOTLE) patients in primary prevention. ${ }^{16-18}$ There was a difference in the percentage of patients with a history of TIA/stroke enrolled in the three RCTs in a comparison of the ROCKET-AF trial with RE-LY and ARISTOTLE. ${ }^{16-18}$ In fact, the ROCKET-AF trial included approximately three times more patients with a history of TIA/stroke (54.9\%) compared to RE-LY $110 \mathrm{mg}(20 \%), 150 \mathrm{mg}(20 \%)$ and ARISTOTLE $(19 \%){ }^{16-18}$

Table 4 summarizes the general characteristics of the populations enrolled in the three RCTs.

\section{Thromboembolic risk in patients with previous transient ischemic attack or stroke}

Figure 2 show the rate of thromboembolic events in patients in primary and secondary prevention treated with DOACs and warfarin in the RE-LY, ROCKET-AF and ARISTOTLE studies. The incidence of ischemic events was higher in patients with a history of previous TIA/stroke than in patients without a history of previous TIA/stroke. In particular, for the primary efficacy end point and for the end point ischemic strokes, the three RCTs all show an increase in the incidence of thrombotic events in secondary prevention both in patients randomized to DOACs and in those randomized to warfarin. ${ }^{16-18}$

\section{Bleeding risk in patients with previous transient ischemic attack or stroke}

Figure 2 shows the rate of bleeding events in patients in primary and secondary prevention treated with DOACs and warfarin in the the RE-LY, ROCKET-AF and ARISTOTLE studies. For the vast majority of safety end points considered in the three RCTs, the incidence of bleeding events was higher in patients with a history of previous TIA/stroke than in patients without a history of previous TIA/stroke. In 
Table 1. Enrollment criteria in phase III randomized clinical trials on DOACs in non-valvular atrial fibrillation.

\begin{tabular}{|c|c|c|}
\hline & INCLUSION & EXCLUSION \\
\hline RE-LY (Dabigatran) & $\begin{array}{l}\text { AF documented in } 12 \text {-leads-ECG or in previous six } \\
\text { months plus at least one of: } \\
\text { previous TIA/stroke/systemic embolism, ejection } \\
\text { fraction }<40 \% \text {, class NYHA } \geq 2 \text { heart failure within } \\
\text { six months before enrollment, age } \geq 75 \text { years } \\
\text { or } 65-74 \text { years when associated to at least one } \\
\text { of diabetes, systemic blood hypertension or coronary } \\
\text { ischemic disease }\end{array}$ & $\begin{array}{l}\text { Age }<18 \text { years, severe valvular heart diseases, stroke in } \\
\text { the previous two weeks or severe stroke (modified Rankin } \\
\text { scale at hospital discharge } 4-5 \text { ), presence of high bleeding } \\
\text { risk conditions, severe renal failure (creatinine clearance } \\
<30 \mathrm{~mL} / \mathrm{min} \text { ), active liver disease, pregnancy }\end{array}$ \\
\hline $\begin{array}{l}\text { ROCKET-AF } \\
\text { (Rivaroxaban) }\end{array}$ & $\begin{array}{l}\text { AF documented at } 12 \text {-leads-ECG plus at least one of: } \\
\text { previous TIA/stroke/systemic embolism or at least } \\
\text { two of heart failure or ejection fraction } \leq 35 \% \text {, } \\
\text { systemic blood hypertension, diabetes, age } \geq 75 \text { years }\end{array}$ & $\begin{array}{l}\text { Age }<18 \text { years, severe mitral valve tenosis, paroxysmal } \\
\text { AF due to cause for reversal, active internal bleeding, } \\
\text { previous severe stroke (modified Rankin scale } 4-5 \text { ) in } \\
\text { the previous three months or stroke in the previous two } \\
\text { weeks, TIA in the previous three days, history of intracranial } \\
\text { bleeding, high bleeding risk conditions, severe renal failure } \\
\text { (creatinine clearance }<30 \mathrm{~mL} / \mathrm{min} \text { ) }\end{array}$ \\
\hline $\begin{array}{l}\text { ARISTOTLE } \\
\text { (Apixaban) }\end{array}$ & $\begin{array}{l}\text { AF documented at } 12 \text {-leads-ECG in two } \\
\text { non-consecutive weeks in the previous } 12 \text { months } \\
\text { plus at least one of: age } \geq 75 \text { years, previous } \\
\text { TIA/stroke/systemic embolism, heart failure in the } \\
\text { previous three months or ejection fraction } \leq 40 \% \text {, } \\
\text { diabetes, systemic blood hypertension }\end{array}$ & $\begin{array}{l}\text { Age }<18 \text { years, AF due to reversal cause, moderate-severe } \\
\text { mitral valve stenosis, presence of conditions in which } \\
\text { anticoagulation is necessary such as mechanical prosthetic } \\
\text { valve, stroke in the previous week, conditions required ASA } \\
\text { at dose }>165 \mathrm{mg} \text { or ASA associated to clopidogrel, } \\
\text { severe renal failure (creatine clearance }<25 \mathrm{~mL} / \mathrm{min} \text { ) }\end{array}$ \\
\hline
\end{tabular}

ECG, electrocardiogram; AF, atrial fibrillation; TIA, transient ischemic attack; ASA, acetylsalicylic acid.

Table 2. Summary of main efficacy and safety results found in phase III randomized clinical trials on DOACs compared with warfarin in non-valvular atrial fibrillation.

\begin{tabular}{|c|c|c|c|c|c|}
\hline END POINTS & $\begin{array}{l}\text { RE-LY } 110 \mathrm{mg} \\
\text { RR }(95 \% \mathrm{CI}) \\
\text { intention to treat }\end{array}$ & $\begin{array}{c}\text { RE-LY } 150 \mathrm{mg} \\
\text { RR }(95 \% \mathrm{CI}) \\
\text { intention to treat }\end{array}$ & $\begin{array}{c}\text { ROCKET-AF } \\
\text { HR }(95 \% \text { CI }) \\
\text { per protocol }\end{array}$ & $\begin{array}{c}\text { ROCKET-AF } \\
\text { HR }(95 \% \text { CI) } \\
\text { intention to teat, } \\
\text { on treatment }\end{array}$ & $\begin{array}{c}\text { ARISTOTLE } \\
\text { HR (95\% CI) } \\
\text { intention to treat for } \\
\text { efficacy, per protocol, } \\
\text { on treatment for safety }\end{array}$ \\
\hline \multicolumn{6}{|c|}{ EFFICACY } \\
\hline Ischemic strokes & $1.11(0.88-1.39)$ & $0.76(0.59-0.97)^{*}$ & $0.94(0.75-1.17)$ & $0.99(0.82-1.20)$ & $0.92(0.74-1.13)$ \\
\hline $\begin{array}{l}\text { Combined end point } \\
\text { ischemic and hemorrhagi } \\
\text { strokes or systemic } \\
\text { embolism }\end{array}$ & $c^{0.90(0.74-1.10)}$ & $0.66(0.52-0.81)^{*}$ & $0.79(0.66-0.96)^{*}$ & $0.88(0.75-1.03)$ & $0.79(0.66-0.95)^{*}$ \\
\hline $\begin{array}{l}\text { Debilitating or } \\
\text { fatal strokes }\end{array}$ & $0.93(0.72-1.21)$ & $0.66(0.50-0.87)^{*}$ & $\mathrm{nr}$ & $\mathrm{nr}$ & $0.71(0.54-0.94)^{*}$ \\
\hline Vascular mortality & $0.90(0.77-1.06)$ & $0.85(0.72-0.99)^{*}$ & $0.89(0.73-1.10)$ & $0.86(0.74-0.99)^{*}$ & $0.89(0.76-1.04)$ \\
\hline Overall mortality & $0.91(0.80-1.03)$ & $0.88(0.77-1.00)$ & $0.85(0.70-1.02)$ & $0.85(0.70-1.02)$ & $0.89(0.80-0.98)^{*}$ \\
\hline Myocardial infarctions & $1.29(0.96-1.75)$ & $1.27(0.94-1.71)$ & $0.81(0.63-1.06)$ & $\mathrm{Nr}$ & $0.88(0.66-1.17)$ \\
\hline \multicolumn{6}{|c|}{ SAFETY } \\
\hline Overall bleedings & $0.78(0.73-0.83)^{*}$ & $0.91(0.85-0.96)^{*}$ & $1.03(0.96-1.11)$ & & $0.71(0.68-0.75)^{*}$ \\
\hline Major bleedings & $0.80(0.70-0.93)^{*}$ & $0.93(0.81-1.07)$ & $1.04(0.90-1.20)$ & & $0.69(0.60-0.80)^{*}$ \\
\hline Fatal bleedings & $0.58(0.35-0.97)^{*}$ & $0.70(0.43-1.14)$ & $0.50(0.31-0.79)$ & & $\begin{array}{c}\mathrm{nr} \\
\text { (Apixaban risk } 0.0037 \\
\text { vs warfarin risk } 0.0060 \text { ) }\end{array}$ \\
\hline Intracranial bleedings & $0.30(0.19-0.45)^{*}$ & $0.41(0.28-0.60)^{*}$ & $0.67(0.47-0.93)^{*}$ & & $0.42(0.30-0.58)^{*}$ \\
\hline Gastrointestinal bleedings & $1.08(0.85-1.38)$ & $1.48(1.18-1.85)^{\circ}$ & $\%$ vs $2.2 \% . \mathrm{P}<0.001^{\circ}$ & & $0.89(0.70-1.15)$ \\
\hline \multicolumn{6}{|c|}{ NET BENEFIT } \\
\hline $\begin{array}{l}\text { Net benefit: vascular } \\
\text { events, major bleedings, } \\
\text { mortality }\end{array}$ & $0.92(0.84-1.01)$ & $0.90(0.82-0.99)$ & $\mathrm{nr}$ & & $0.85(0.78-0.92)^{*}$ \\
\hline
\end{tabular}

CI, confidence interval; nr, not reported. *Superiority; ${ }^{\circ}$ inferiority; the other, no inferiority. 
particular, for the end point intracranial bleedings, all three RCTs show higher incidence in secondary prevention both in patients randomized to DOACs and in those randomized to warfarin. ${ }^{16-18}$

\section{Efficacy and safety of DOACs in secondary prevention}

Tables 5 and 6 summarize the results of efficacy and safety of the DOACs compared with warfarin and analyzed according to primary and secondary prevention.

\section{Efficacy end points}

For all efficacy end points, DOACs in secondary prevention maintain the objective of non-inferiority when compared to warfarin. ${ }^{16-18}$

Dagibatran: the lower dose of dabigatran $(110 \mathrm{mg}$ twice/day), which was not inferior to warfarin in primary prevention on all efficacy end points, becomes superior to warfarin in end points regarding vascular mortality and total mortality in secondary prevention. ${ }^{16}$ The higher dose of dabigatran (150 mg twice/day), which was superior to warfarin for all efficacy end points in primary prevention, was found to be not inferior to warfarin in secondary prevention for the same end points.

Rivaroxaban: rivaroxaban is not inferior to warfarin for the vast majority of efficacy end points in primary and secondary prevention, being superior to warfarin only on the end point disabling or fatal stroke in primary prevention.

Apixaban: apixaban is superior to warfarin on the end point disabling or fatal stroke both in primary and secondary prevention, while on all other efficacy end points apixaban is not inferior to warfarin in either context of prevention.

Figure 3 shows the RRR for total mortality with DOACs compared to warfarin.

Overall, DOACs reduce the RR of ischemic and hemorrhagic strokes and systemic embolism in secondary prevention in a range between $6 \%$ for rivaroxaban (HR $0.94,95 \%$ CI: $0 \cdot 77-1 \cdot 16)$ and $25 \%$ for dabigatran 150 mg twice/day (RR 0.75, 95\% CI: 0.52-1.08) while this range is between $7 \%$ for dabigatran $110 \mathrm{mg}$ twice/day

Table 3. Summary of main efficacy and safety results expressed with absolute risk reduction and number needed to treat or number needed to harm found in phase III randomized clinical trials on DOACs compared to warfarin in non-valvular atrial fibrillation.

\begin{tabular}{|c|c|c|c|c|c|c|c|c|}
\hline END POINTS & $\begin{array}{l}-\mathrm{LY} 110 \mathrm{mg} \\
\text { ntion to tres }\end{array}$ & & $\begin{array}{l}\text { RE-LY } 150 \mathrm{mg} \\
\text { intention to treat }\end{array}$ & +3 & $\begin{array}{l}\text { ROCKET-AF } \\
\text { per protocol, } \\
\text { on treatment }\end{array}$ & & $\begin{array}{c}\text { ARISTOTLE } \\
\text { intention to } \\
\text { treat for efficacy, } \\
\text { per protocol on } \\
\text { treatment for safety }\end{array}$ & \\
\hline & ARR/1000 & NNT & ARR/1000 & NNT & ARR/1000 & NNT & ARR/1000 & NNT \\
\hline & & & EFFIC & $\mathbf{A C Y}$ & & & & \\
\hline $\begin{array}{l}\text { Combined end point } \\
\text { ischemic and hemorrhagic } \\
\text { strokes or systemic embolism }\end{array}$ & 1.6 & 625 & $5.8^{*}$ & $172 *$ & $5.0^{*}$ & $200 *$ & $3.3 *$ & $303^{*}$ \\
\hline Ischemic strokes & -1.4 & 714 & $2.8^{*}$ & $357^{*}$ & 1.6 & 625 & 0.8 & 1250 \\
\hline Debilitating or fatal strokes & 0.6 & 1666 & $3.4^{*}$ & $294^{*}$ & 4.7 & 212 & $\mathrm{nr}^{*}$ & $\mathrm{nr}^{*}$ \\
\hline Vascular mortality & 2.6 & 384 & $3.9^{*}$ & $256^{*}$ & 3.2 & 312.5 & $\mathrm{nr}$ & $\mathrm{nr}$ \\
\hline Overall mortality & 3.8 & 263 & 4.9 & 204 & 5.8 & 172 & $4.2^{*}$ & $238^{*}$ \\
\hline & & & SAFI & TY & & & & \\
\hline Myocardial infarctions & -1.8 & 555 & -1.7 & 588 & -3.5 & 285 & $0.8^{*}$ & $1250^{*}$ \\
\hline Overall bleedings & $35.3 *$ & $28^{*}$ & $17.3^{*}$ & $58^{*}$ & -4 & 250 & $19.4 *$ & $51^{*}$ \\
\hline Major bleedings & $6.5^{*}$ & $154^{*}$ & 2.5 & 400 & -2 & 500 & $7.3 *$ & $137 *$ \\
\hline Fatal bleedings & nr* & & $\mathrm{nr}$ & & 3 & 333 & $\mathrm{nr}$ & $\mathrm{nr}$ \\
\hline Intracranial bleedings & $5.1^{*}$ & $196^{*}$ & $4.4^{*}$ & $227^{*}$ & $2 *$ & $500^{*}$ & $4.7^{*}$ & $212 *$ \\
\hline Gastrointestinal bleedings & -1.0 & 1000 & $-4.9^{\circ}$ & $204^{\circ}$ & $-10^{\circ}$ & $100^{\circ}$ & 1 & 1000 \\
\hline & & & NET BE & NEFIT & & & & \\
\hline $\begin{array}{l}\text { Net benefit: vascular events, } \\
\text { major bleedings, mortality }\end{array}$ & 5.5 & 181 & $7.3^{*}$ & $137^{*}$ & $\mathrm{nr}$ & $\mathrm{nr}$ & $9.4 *$ & $106^{*}$ \\
\hline
\end{tabular}

ARR, absolute risk reduction; NNT, number needed to treat. *Superiority; 'inferiority; the other, no inferiority. Positive numbers are associated to NNT of DOACs on warfarin, negative numbers are associated with number needed to harm of DOACs on warfarin. 
(A)

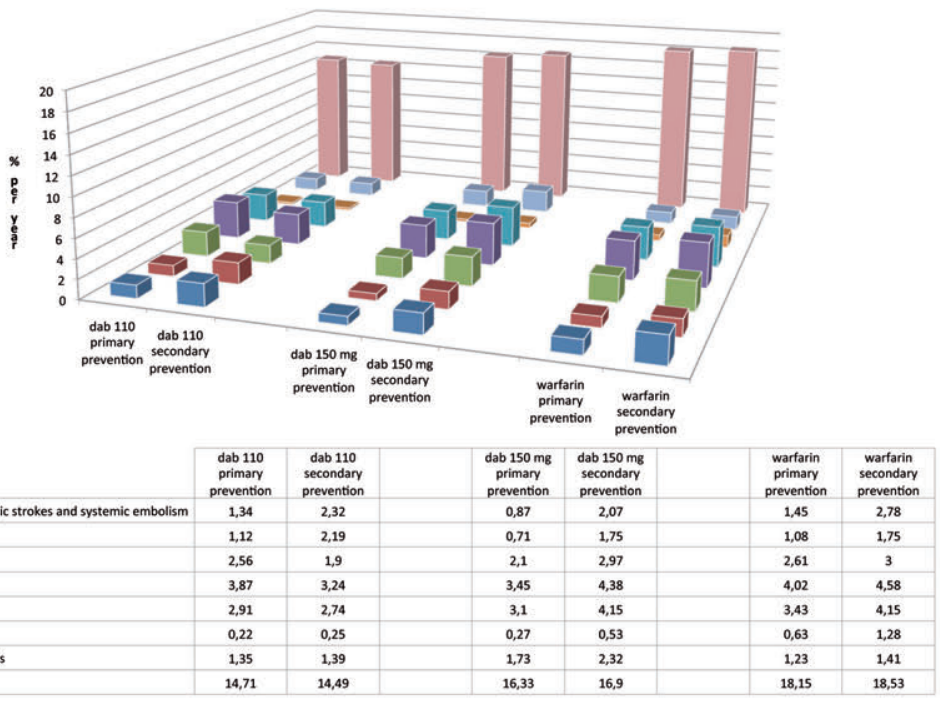

(B)

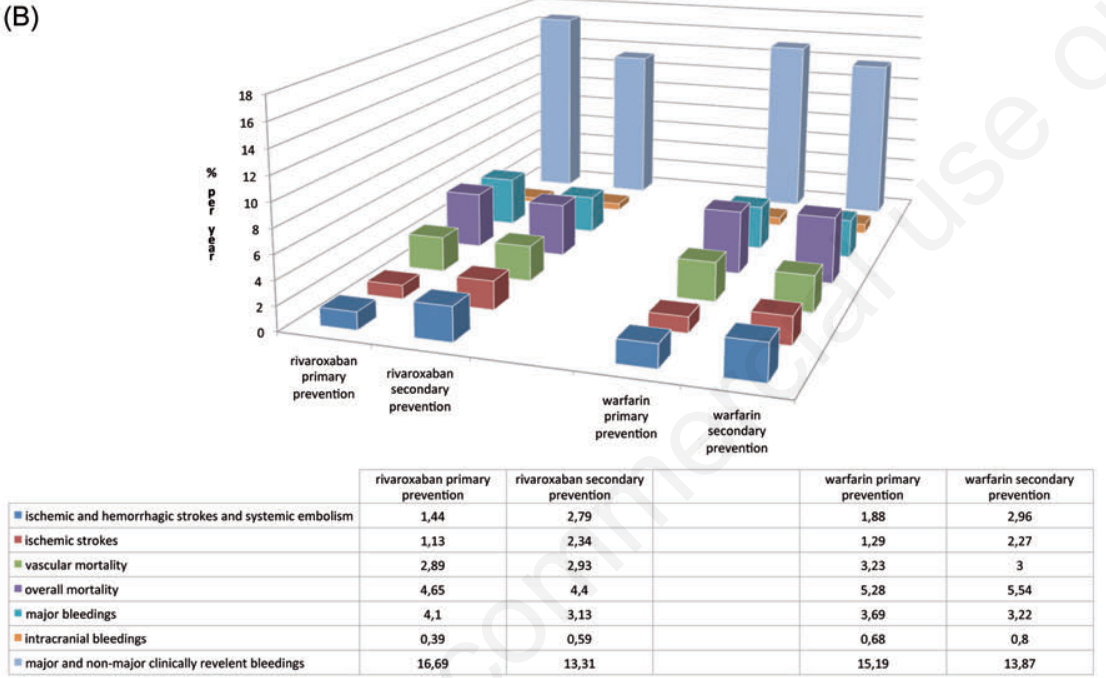

(C)

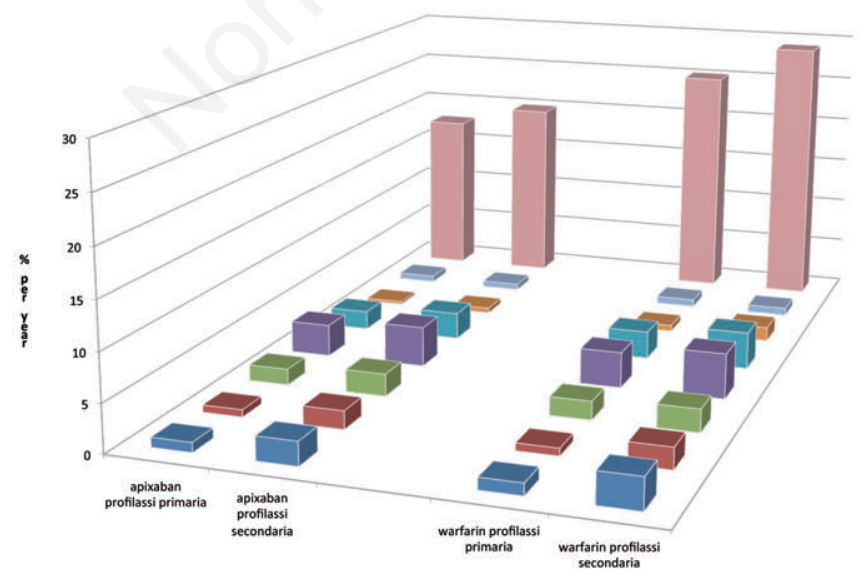

\begin{tabular}{|l|c|c|c|c|}
\cline { 2 - 5 } \multicolumn{1}{c|}{} & $\begin{array}{c}\text { apixaban profilassi } \\
\text { primaria }\end{array}$ & $\begin{array}{c}\text { apixaban profilassi } \\
\text { secondaria }\end{array}$ & wartarin profilassi primaria & $\begin{array}{c}\text { wartarin profliassi } \\
\text { secondaria }\end{array}$ \\
\hline " ischemic and hemorrhagic strokes and systemic embolism & 1,01 & 2,46 & 1,23 & 3,24 \\
\hline " ischemic stroke & 0,76 & 1,92 & 0,79 & 2,23 \\
\hline " vascular mortality & 1,68 & 2,35 & 1,94 & 2,41 \\
\hline "overall mortality & 3,37 & 4,22 & 3,75 & 4,77 \\
\hline " major bleedings & 1,98 & 2,84 & 2,91 & 3,91 \\
\hline "intracranial bleedings & 0,29 & 0,55 & 0,65 & 1,49 \\
\hline " gastrointestinal bleedings & 0,68 & 0,66 & 0,78 & 0,8 \\
\hline "overall bleedings & 17,7 & 19,86 & 25,11 & 29,12 \\
\hline
\end{tabular}

Figure 2. A) Events rate in the RE-LY study; B) Events rate in the ROCKET-AF study; C) Events rate in the ARISTOTLE study. 
(RR $0.93,95 \%$ CI: $0.73-1.18$ ) and $40 \%$ for dabigatran $150 \mathrm{mg}$ twice/day (RR 0.60, 95\% CI: 0.45-0.78) in primary prevention ${ }^{16-18}$ (Figure 4).

The different results of DOACs in primary and secondary prevention impacts on the values of NNT and number needed to harm (required number of patients treated to cause an adverse event, NNH) (Table 6). For the majority of efficacy end points, dabigatran $110 \mathrm{mg}$ twice/day significantly reduces the value of its NNTs in secondary prevention compared to primary prevention with the exception of the end point ischemic stroke where the $\mathrm{NNH}$ is 227 in secondary prevention, down from 2500 in primary prevention. ${ }^{16}$ In contrast, dabigatran $150 \mathrm{mg}$ twice/day increases its NNT values in secondary prevention. ${ }^{16}$ In the ROCKET-AF study, rivaroxaban NNT values increase in the efficacy end points in secondary prevention, while in the ARISTOTLE study, apixaban in this context is associated with a reduction in NNTs with the exception of the end point fatal or disabling stroke. ${ }^{17,18}$

\section{Safety end points}

For all safety end points, DOACs maintain the objective of non-inferiority when compared to warfarin in secondary prevention, ${ }^{16-18}$ with the only exception of the inferiority of higher dose of dabigatran $(150 \mathrm{mg}$ twice/day) on warfarin in the gastrointestinal bleedings end point, increasing the relative risk of $24 \%$ in secondary prevention versus primary prevention. ${ }^{16}$ Data on gastrointestinal bleedings in secondary prevention for rivaraxaban, which resulted inferior to warfarin in this context, are not available. ${ }^{13,17}$

Dabigatran: lower dose of dabigatran $(110 \mathrm{mg}$ twice/day) is superior to warfarin both in primary and secondary prevention end point on major bleedings and not inferior to warfarin in the gastrointestinal bleedings end point. ${ }^{16}$ Higher dose of dabigatran dose (150 mg twice/day) is not inferior to warfarin on major bleedings. ${ }^{17}$ For dabigatran, data on total and fatal bleedings according to primary and secondary prevention are not reported. In the total population of RE-LY, dabigatran $110 \mathrm{mg}$ resulted superior to warfarin on total and fatal bleedings, dabigatran $150 \mathrm{mg}$ was not inferior to warfarin in total and fatal bleedings. ${ }^{12}$ Dabigatran $110 \mathrm{mg}$ increases the superiority on warfarin in secondary prevention with respect to major bleedings, bringing the RRR from $15 \%$ to $34 \%{ }^{16}$ (Figure 3 ).

Rivaroxaban: rivaroxaban is superior to warfarin in primary and secondary prevention on fatal bleedings, while it is not inferior in either context of prevention on total bleedings. ${ }^{17}$

Apixaban: apixaban is superior to warfarin in the major bleedings end point and not inferior on the gastrointestinal bleedings end point both in primary and secondary prevention. ${ }^{18}$ Data on major and fatal bleedings for apixaban according to primary and secondary prevention are not available. ${ }^{18}$

Table 4. General characteristics of patients enrolled in RE-LY, ROCKET-AF and ARISTOTLE studies according to primary and secondary prevention.

\begin{tabular}{|c|c|c|c|c|c|c|c|c|}
\hline & \multicolumn{2}{|c|}{$\begin{array}{r}\text { RE-LY } 110 \text { mg } \\
\text { (Dabigatran) }\end{array}$} & \multicolumn{2}{|c|}{$\begin{array}{c}\text { RE-LY } 150 \text { mg } \\
\text { (Dabigatran) }\end{array}$} & \multicolumn{2}{|c|}{$\begin{array}{l}\text { ROCKET-AF } \\
\text { (Rivaroxaban) }\end{array}$} & \multicolumn{2}{|c|}{$\begin{array}{r}\text { ARISTOTLE } \\
\text { (Apixaban) }\end{array}$} \\
\hline & $\begin{array}{c}\text { Primary } \\
\text { prevention }\end{array}$ & $\begin{array}{l}\text { Secondary } \\
\text { prevention }\end{array}$ & $\begin{array}{c}\text { Primary } \\
\text { prevention }\end{array}$ & $\begin{array}{l}\text { Secondary } \\
\text { prevention }\end{array}$ & $\begin{array}{c}\text { Primary } \\
\text { prevention }\end{array}$ & $\begin{array}{l}\text { Secondary } \\
\text { prevention }\end{array}$ & $\begin{array}{c}\text { Primary } \\
\text { prevention* }\end{array}$ & $\begin{array}{l}\text { Secondary } \\
\text { prevention* }\end{array}$ \\
\hline Number & 4819 & 1195 & 4843 & 1233 & 3377 & 3754 & 7426 & 1694 \\
\hline Age (years) & $\begin{array}{l}71.7 \pm 8.4 \\
\text { (median) }\end{array}$ & $\begin{array}{l}70.7 \pm 9.4 \\
\text { (median) }\end{array}$ & $71.7 \pm 8.5$ & $70.8 \pm 10.1$ & $\begin{array}{c}75 \\
\text { (median) }\end{array}$ & 71 & $68.8 \pm 9.7$ & $70.1 \pm 9.5$ \\
\hline Males/females & $64.3 / 35.7 \%$ & $64.1 / 35.9 \%$ & $63.5 / 36.5 \%$ & $62.2 / 37.8 \%$ & $60 / 40 \%$ & $61 / 39 \%$ & $65 / 35 \%$ & $63 / 37 \%$ \\
\hline $\mathrm{CHADS}_{2} \geq 2$ & $59.4 \%$ & $100 \%$ & $59.5 \%$ & $100 \%$ & $100 \%$ & $100 \%$ & $58 \%$ & $100 \%$ \\
\hline $\mathrm{CHADS}_{2} \geq 3$ & $18.5 \%$ & $90 \%$ & $17.9 \%$ & $90.2 \%$ & $\mathrm{nr}^{\circ}$ & $\mathrm{nr}^{\circ}$ & $16 \%$ & $92 \%$ \\
\hline ASA at moment of enrollment & ht $\quad 40 \%$ & $39.9 \%$ & $38.4 \%$ & $39.7 \%$ & $35 \%$ & $38 \%$ & $31 \%$ & $31 \%$ \\
\hline $\begin{array}{l}\text { Previous acute myocardial } \\
\text { infarction }\end{array}$ & $\mathrm{nr}$ & $\mathrm{nr}$ & $\mathrm{nr}$ & $\mathrm{nr}$ & $19 \%$ & $14 \%$ & $14 \%$ & $17 \%$ \\
\hline Systemic blood hypertension & $79.2 \%$ & $77 \%$ & $79.3 \%$ & $77.3 \%$ & $96 \%$ & $85 \%$ & $88 \%$ & $83 \%$ \\
\hline Diabetes & $23.7 \%$ & $22.4 \%$ & $22.9 \%$ & $23.7 \%$ & $58 \%$ & $25 \%$ & $25 \%$ & $26 \%$ \\
\hline Heart failure & $\mathrm{nr}$ & $\mathrm{nr}$ & $\mathrm{nr}$ & $\mathrm{nr}$ & $76 \%$ & $51 \%$ & $31 \%$ & $27 \%$ \\
\hline Paroxysmal AF & $\mathrm{nr}$ & $\mathrm{nr}$ & $\mathrm{nr}$ & $\mathrm{nr}$ & $16 \%$ & $19 \%$ & $\mathrm{nr}$ & $\mathrm{nr}$ \\
\hline Persistent or permanent $\mathrm{AF}$ & $\mathrm{nr}$ & $\mathrm{nr}$ & $\mathrm{nr}$ & $\mathrm{nr}$ & $84 \%$ & $81 \%$ & $\mathrm{nr}$ & $\mathrm{nr}$ \\
\hline
\end{tabular}

$\mathrm{nr}$, not reported (exclusively patients in primary or secondary prevention). In phase III randomized clinical trials, reporting on overall patient data are expressed in detail.

*ARISTOTELE study data refer to sum of patients treated with apixaban or warfarin with previous TIA/stroke versus patients treated with apixaban or warfarin without previous TIA/stroke.; ${ }^{\circ}$ ROCKET-AF study patients with CHADS2 $\geq 2$ represent $100 \%$ and with CHADS $2 \geq 3.87 \%$. 


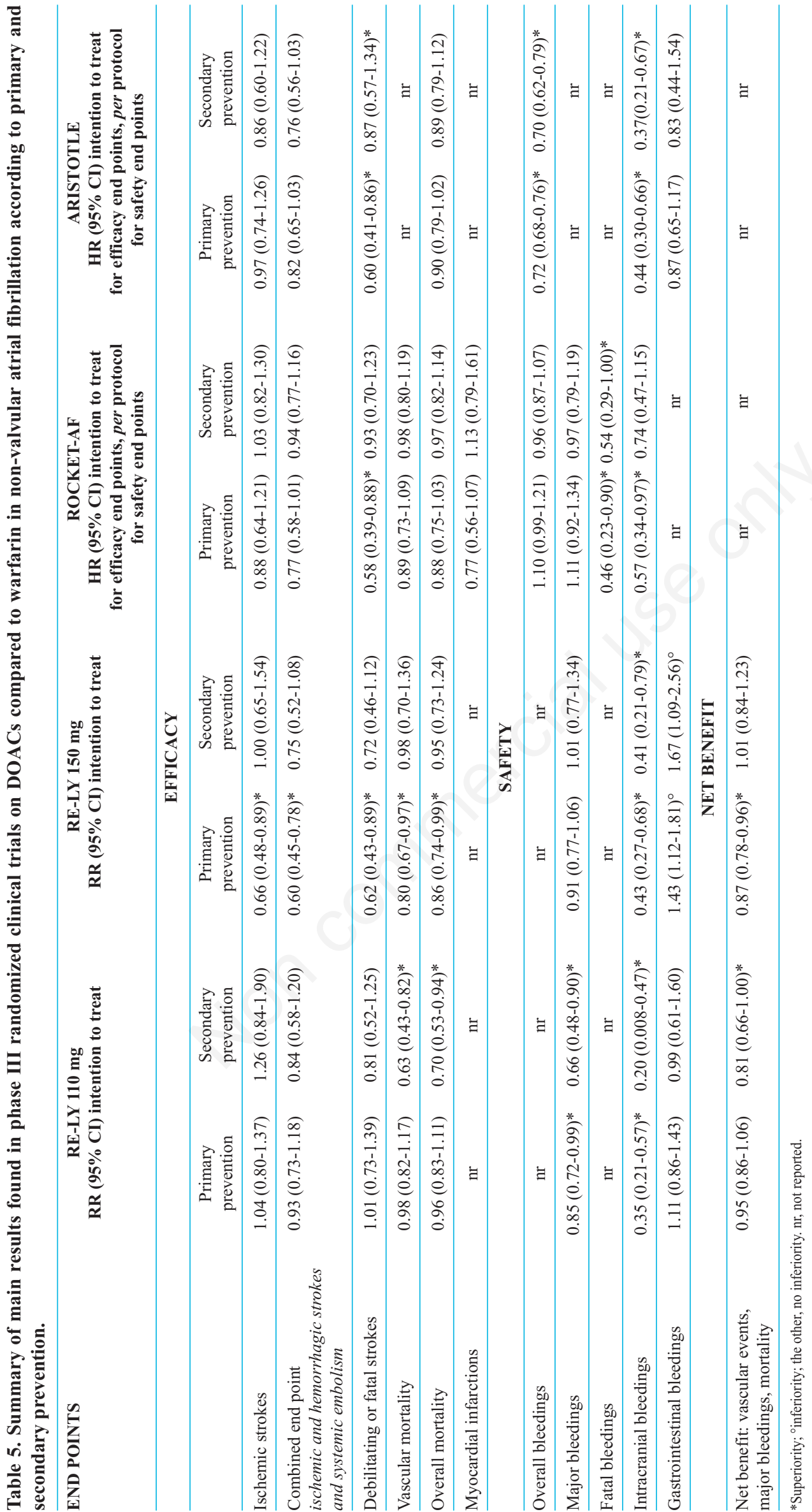


The most important result emerged in the phase III RCTs on DOACs in NVAF is represented by the RRR of intracranial bleedings, which was overall $55 \% .{ }^{19}$ The analysis of intracranial bleeding risk within RCTs in terms of primary and secondary prevention shows that both doses of dabigatran and apixaban are superior to warfarin in both contexts whereas rivaroxaban is superior on this end point in primary prevention compared to warfarin and not inferior in secondary prevention (RR 0.74, 95\% CI: 0.47-1.15) ${ }^{16-18}$ The overall incidence of intracranial bleeding in patients on DOACs for secondary prevention was $0.90 \%$ per 100 patients treated $(0.51 \%$ in primary prevention) while it was $1.84 \%$ per 100 patients treated with warfarin $(1.14 \%$ in primary prevention), with an overall RR of 0.48 and an RRR of $52 \%$ (56\% in primary prevention) (Figure 5 ).

Dabigatran $110 \mathrm{mg}$ twice/day significantly reduces the value of its NNTs in secondary prevention compared to primary prevention, even increasing the $\mathrm{NNH}$ on the gastrointestinal bleedings end point ( 1 in every 5000 patients treated for secondary prevention develops a gastrointestinal bleeding $v s 1$ in 833 in primary prevention), while dabigatran $150 \mathrm{mg}$ twice/day significantly reduces the advantages in efficacy when compared with warfarin in secondary prevention, increasing the values of its NNTs and further reducing the $\mathrm{NNH}$ for the end point gastrointestinal bleeding. ${ }^{16}$ In the ROCKET-AF study, in secondary prevention rivaroxaban reduces its advantages on safety end points related to intracranial and fatal bleedings compared to warfarin, increasing the values of NNTs and has disadvantages for the total and major bleedings, passing from an NNT to an NNH. ${ }^{17}$ Finally, in the ARISTOTLE study, apixaban is associated with a reduction in the values of NNTs in all safety end points in secondary prevention compared to primary prevention. ${ }^{18}$

\section{Net clinical benefit}

In secondary prevention, dabigatran at lower dose (110 mg twice/day) reaches superiority over warfarin in net benefit (non-inferiority on this end point compared to warfarin in primary prevention), while the higher dose (150 mg twice/day) results not inferior to warfarin (it was superior to warfarin in primary prevention) (Table 5). The net benefit of rivaroxaban and apixaban on warfarin in secondary prevention has not been reported in the post hoc analyses; net benefit was greater for apixaban in the overall population, while it was not reported in the ROCKET-AF study for rivaroxaban (Table 2).

\section{Discussion}

Patients with NVAF and history of previous TIA/stroke have a risk of recurrent embolism ap- proximately three times higher compared to patients without history of TIA/stroke. ${ }^{5}$ In this subgroup of patients, VKAs was seen to have the higher net benefit with an NNT of $14 .{ }^{9}$ However, these patients are more complex in clinical practice compared with patients without history of TIA/stroke, presenting a higher bleeding risk. ${ }^{9}$

The differences emerging in secondary prevention can have important implications for clinical practice. First, DOACs are not inferior to warfarin for almost all of the efficacy and safety end points also in secondary prevention of patients with NVAF. In these patients at higher cardioembolic and hemorrhagic risk, DOACs are effective and safe alternatives, with several advantages in terms of pharmacokinetic and pharmacodynamic profile.

The analysis of phase III RCTs by dividing the patients into those with a prior history of TIA/stroke and those with no history of such events, clearly confirms that the patients in secondary prevention have an overall increased embolic and bleeding risk. In the RE-LY study, dabigatran at lower dose (110 mg twice/day), despite its association with a higher rate of ischemic and hemorrhagic stroke and systemic embolism compared to the higher dose (150 $\mathrm{mg}$ twice/day) both in primary and in secondary prevention, shows a superior net clinical benefit compared to warfarin due to a reduction in bleeding events. ${ }^{16-18}$ In contrast, superiority of dabigatran at higher dose on warfarin in the net clinical benefit is lost in secondary prevention as the result of an increased rate of bleedings. ${ }^{16-18}$ In secondary prevention, rivaroxaban and apixaban seem to lose some advantage over warfarin in terms of some benefits that had characterized them in the overall analysis of their RCTs, such as the significant reduction in intracranial bleedings and disabling or fatal strokes for rivaroxaban, and significant reduction in total mortality for apixaban. However, never losing their non-inferiority to warfarin. ${ }^{17,18}$

From a practical point of view, the use of DOACs is also desirable and recommended in secondary prevention, especially considering the RRR of $52 \%$ compared to warfarin with a range from $26 \%$ for rivaroxaban (HR $0.74,95 \%$ CI: $0.47-1.15$ ) to $80 \%$ for dabigatran $110 \mathrm{mg}$ (RR $0.20,95 \%$ CI: 0.08-0.47) for an end point of utmost importance such as intracranial bleedings. ${ }^{16-18}$

However, in clinical practice, despite the fact that to date no recommendations have been made regarding changing the dose of DOACs in secondary cardioembolic stroke prevention, it could be suggested to prefer DOACs or dosages of DOACs which have demonstrated the best efficacy/safety profile. As recently demonstrated by a meta-analysis of Rasmussen et al. in which DOACS were indirectly compared with each other, lower dabigatran dose (110 mg twice/day) 


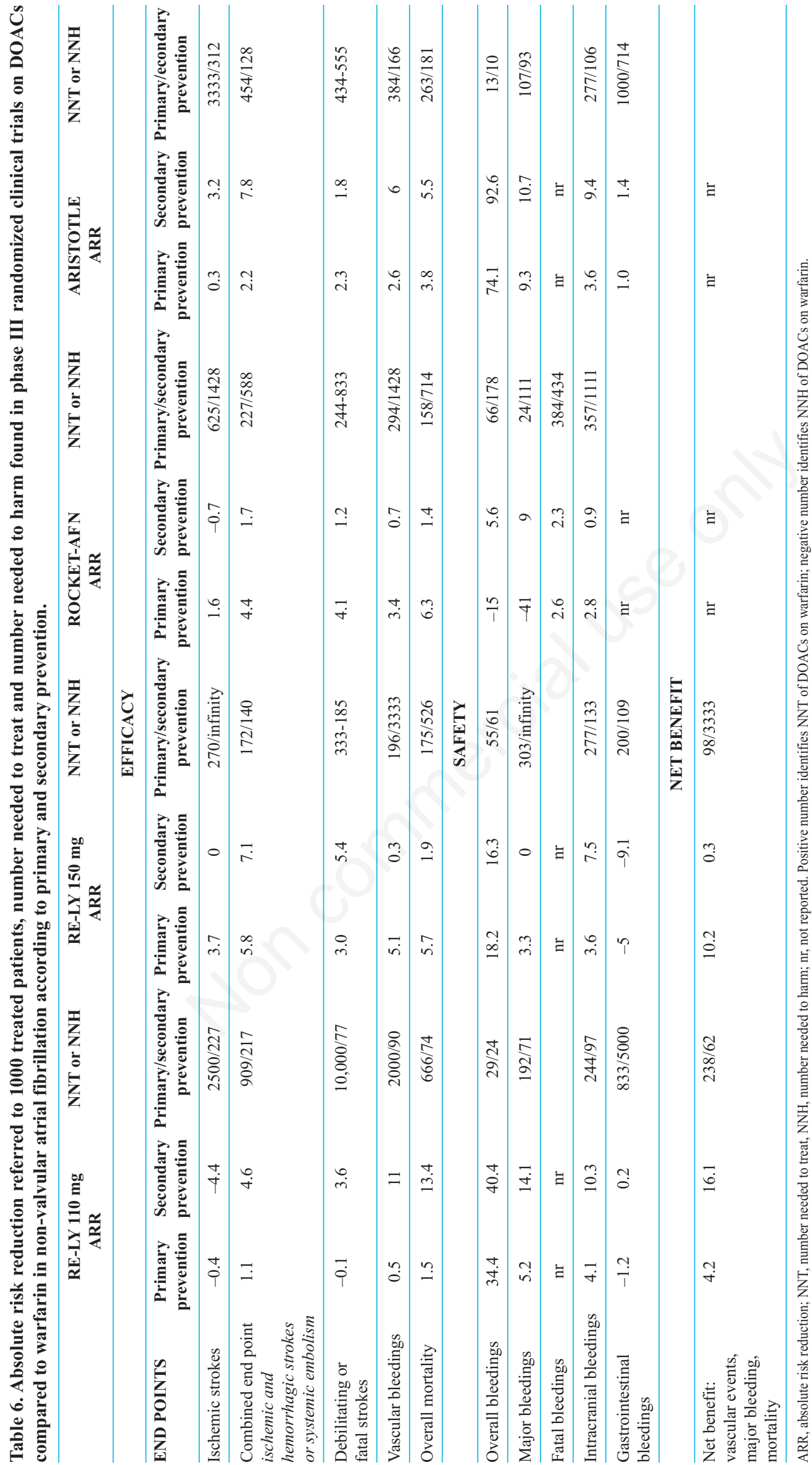


should show such a good efficacy/safety profile. However, as pointed out by the Authors, this can only be confirmed through direct comparisons. ${ }^{22}$

In this context, it is also interesting to refer to the recent publication of the post hoc analysis of the AVERROES study, a phase III RCT in which apixaban at a dose of $5 \mathrm{mg}$ twice/day was compared with
ASA (80-325 mg) for cardioembolic prophylaxis in patients with NVAF who are not suitable for VKAs treatment. Apixaban reduced the RR of ischemic and hemorrhagic stroke and systemic embolism by $71 \%$ compared to ASA in secondary prevention without there being any significant difference in major and intracranial bleedings..$^{23}$

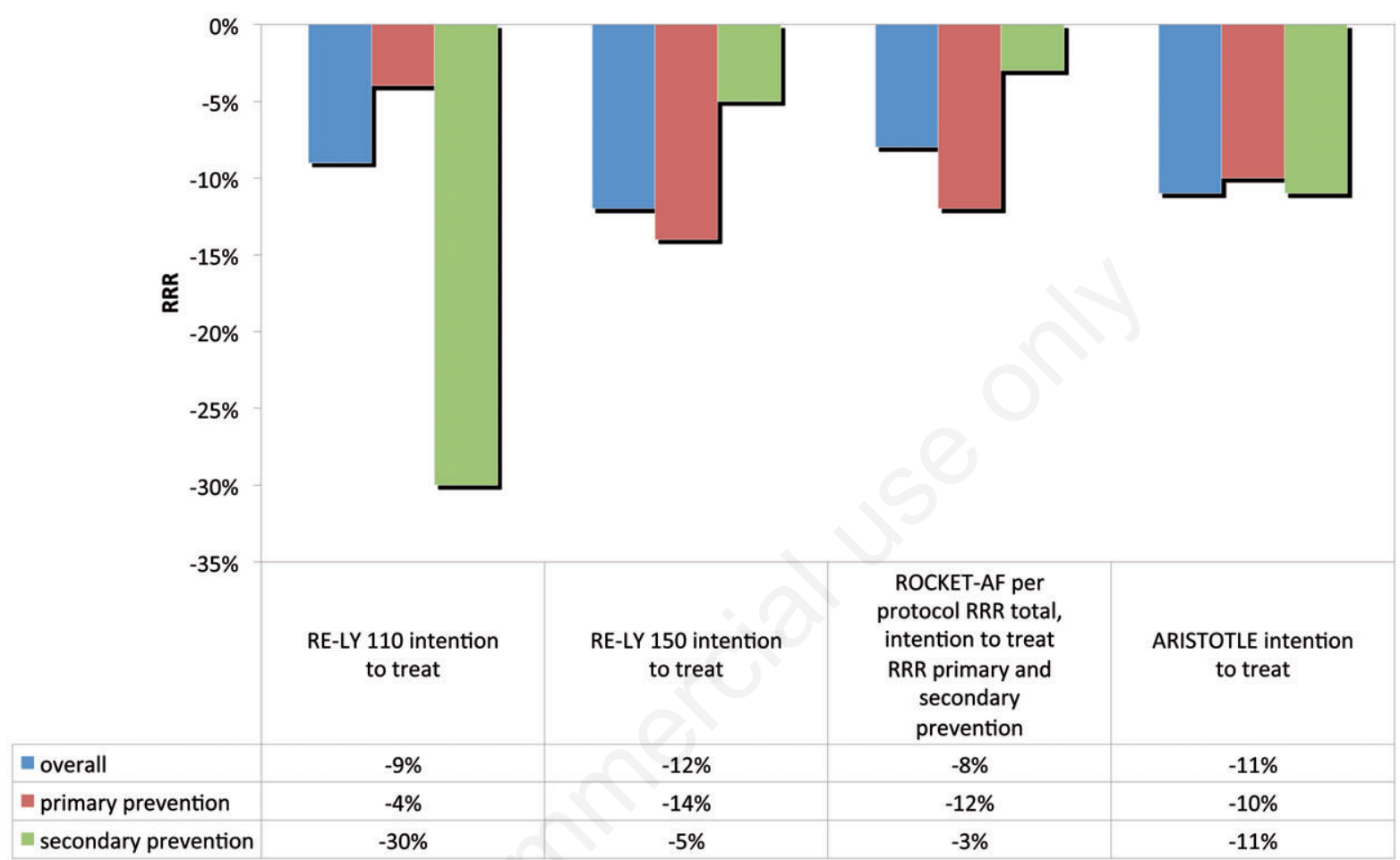

Figure 3. Relative risk reduction (RRR) of all causes mortality with DOACs compared to warfarin.

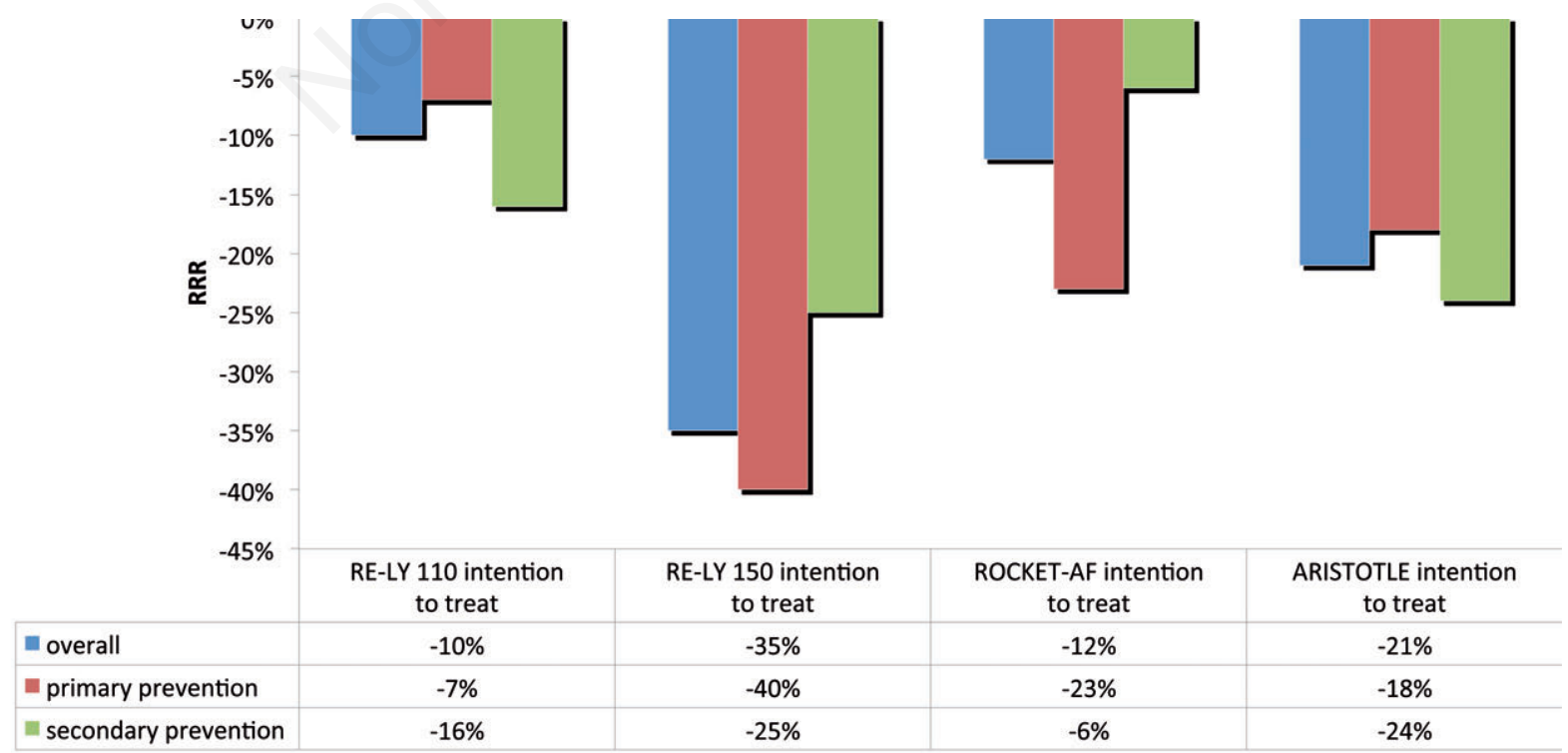

Figure 4. Relative risk reduction (RRR) of strokes and systemic embolism with DOACs compared to warfarin. 


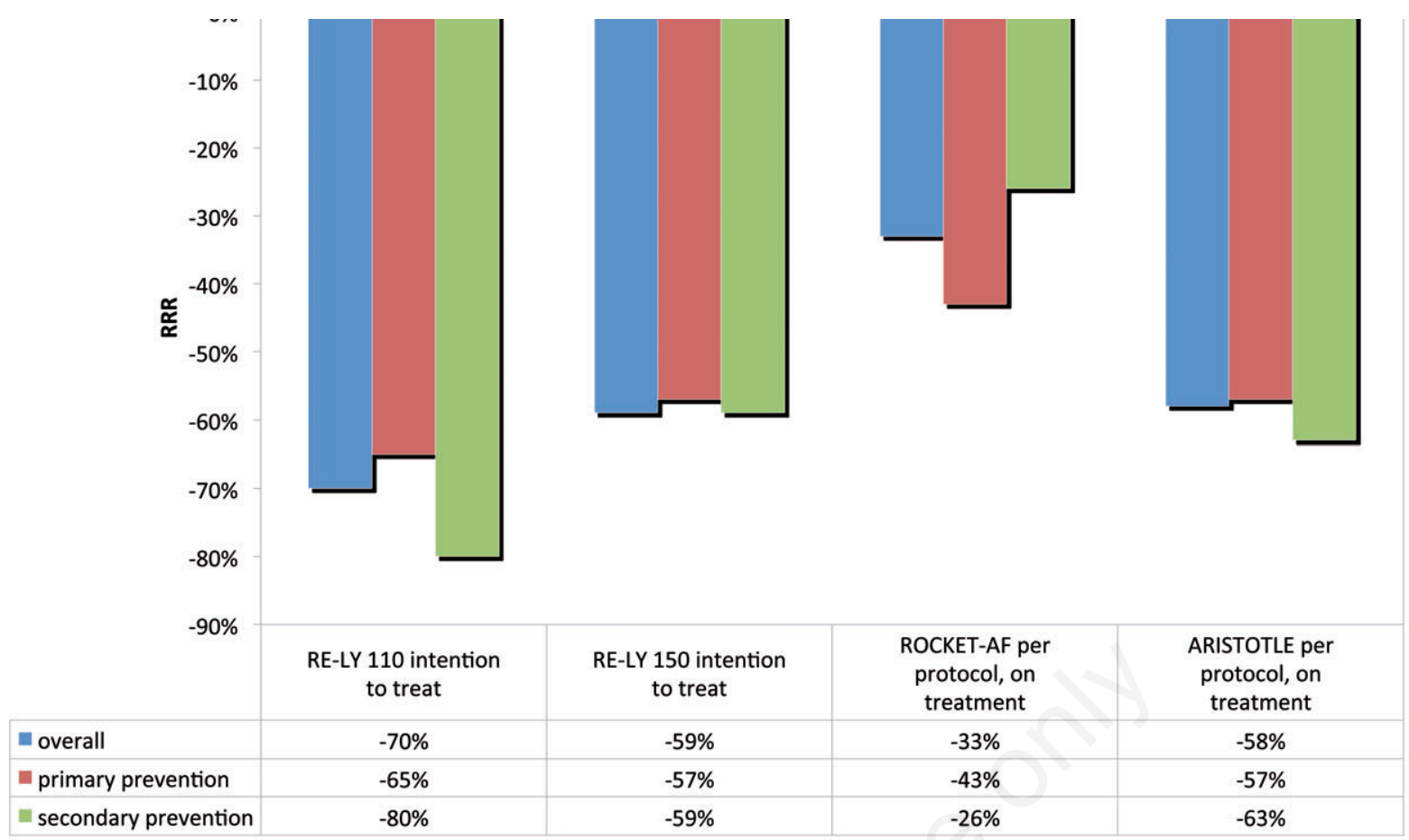

Figure 5. Relative risk reduction (RRR) of intracranial bleedings with DOACs compared to warfarin.

\section{Concerns in secondary prevention: when to start DOACs in the acute phase of cardioembolic stroke?}

The patient with cardioembolic stroke associated with NVAF should receive antithrombotic drugs for secondary prevention already from the acute phase of stroke. DOACs are not inferior (and are for many aspects superior) to warfarin for cardioembolic prevention and the most recent guidelines suggest using DOACs and not VKA for this purpose.$^{5,8}$ However, some uncertainty remains about when to start DOACs in the acute phase of a cardioembolic stroke. Although there is no uniformity on VKA management in the acute phase of a cardioembolic stroke, it is now quite clear that the optimal timing for introducing VKAs in the acute phase of stroke is represented by the period ranging from $48 \mathrm{~h}$ to 14 days after accurate exclusion of severe neurological deterioration, wide extension of ischemic injury and embolic cardiac comorbidity. ${ }^{24}$ Instead, subjects with clinically severe stroke, with a large ischemic lesion and absence of cardiac conditions such as atrial or ventricular thrombosis or mechanical prosthetic valves which may be at high risk of early embolic recurrence, should start VKAs after 14 days. ${ }^{24}$ In phase III RCTs on DOACs in NVAF, patients with recent cardioembolic stroke were excluded. With the exception of the ARISTOTLE study with apixaban, which included patients with previous stroke occurring within seven days of enrollment, the RE-LY and ROCKET-AF studies excluded patients with previous non-severe stroke occurring within 14 days and severe stroke occurring within 3-6 months of enrollement (Table 1). ${ }^{12-14}$ It should be noted, however, that the ARISTOTLE study included only 44 patients with stroke occurring 7-14 days before enrollement of whom 23 were randomized to warfarin and 21 to apixaban. ${ }^{14}$ Therefore, due to lack of evidence, when to start a DOACs in secondary prevention after an acute cardioembolic stroke remains a subject of debate. Very recently, recommendations for the management of DOACs in clinical practice have been made widely available. ${ }^{25-29}$ In the context of the acute phase of cardioembolic stroke, recommendations on dabigatran suggest starting it immediately after a TIA, 3-5 days after a clinically mild stroke, after 5-7 days in patients with a stroke of moderate severity, approximately 14 days or more in patients with severe cardioembolic stroke. ${ }^{25-27}$ Other clinical management experts have made similar suggestions for rivaroxaban. Rivaroxaban should be started immediately after a TIA, and between $48 \mathrm{~h}$ to 14 days after a stroke, taking into account clinical severity, lesion extension at neuroimaging, and cardiological comorbidity by echocardiography. ${ }^{29}$

However, there are no recommendations as to which dosage should be chosen. The acute phase of cardioembolic stroke is a well-recognized period of high risk and the incidence and risk factors of hemor- 
rhagic transformation related to the use of DOACs in this phase are still not known. Therefore, the balance between risk of embolic recurrence and hemorrhagic transformation should focus on selecting the right anticoagulation and its dose, taking into account the fact that the anticoagulant effect of DOACs is almost immediate. The choice of which DOACs to use or at what dosage in the acute phase of a cardioembolic stroke should take into account its efficacy/safety profile, the risk of recurrent embolism, bleeding risk, concomitant use of drugs, or presence of comorbidity or conditions that increase the plasma concentration of the DOACs, such as renal or liver failure. Available data show that a lower dose of dabigatran $(110 \mathrm{mg}$ twice/day) seems to have the best benefit/risk profile and, therefore, may be the preferred choice. However, it must be said that all available data are derived from an indirect comparison of DOACs based on the results of the phase III RCTs. None of the RCTs carried out so far have made a head-to-head comparison between DOACs, and neither have there been any phase IV clinical studies aiming to widen our understanding of this issue.

\section{Conclusions}

Results of the three mega RCTs on DOACs in NVAF focused on patients with previous TIA/stroke show that new drugs maintain non-inferiority against warfarin, but also show that superiority in some end points may be lost for non-inferiority in the secondary prevention, at least for the higher dose of dabigatran (150 mg twice/day), rivaroxaban and apixaban. Instead, a lower dose of dabigatran (110 $\mathrm{mg}$ twice/day) seems to acquire more advantages versus warfarin in terms of efficacy and safety, especially in net benefit, in this context. The future use of DOACs in clinical practice should serve to confirm the different findings that have emerged in secondary compared to primary prevention.

\section{References}

1. Go AS, Hylek EM, Phillips KA, et al. Prevalence of diagnosed atrial fibrillation in adults: national implications for rhythm management and stroke prevention: the AnTicoagulation and Risk Factors in Atrial Fibrillation (ATRIA) study. JAMA 2001;285:2370-5.

2. Miyasaka Y, Barnes ME, Gersh BJ, et al. Secular trends in incidence of atrial fibrillation in Olmsted County, Minnesota, 1980 to 2000, and implications on the projections for future prevalence. Circulation 2006;114: 119-25.

3. Heeringa J, van der Kuip DAM, Hofman A, et al. Prevalence, incidence, and lifetime risk of atrial fibrillation: the Rotterdam study. Eur Heart J 2006;27:949-53.

4. Campanini M, Frediani R, Artom A, et al. Real-world management of atrial fibrillation in Internal Medicine units: the FADOI 'FALP' observational study. J Cardiovasc Med (Hagerstown) 2013:14:26-34.

5. Camm AJ, Lip GY, De Caterina R; ESC Committee for Practice Guidelines (CPG). 2012 Focused update of the ESC guidelines for the management of atrial fibrillation. An update of 2010 ESC guidelines for the management of atrial fibrillation. Eur Heart J 2012;33:2719-47.

6. Fuster V, Ryden LE, Connom DS, et al. American College of Cardiology Foundation/American Heart Association Task Force. 2011 ACCF/AHA/HRS focused updates incorporated into the ACC/AHA/ESC 2006 guidelines for the management of patients with atrial fibrillation: a report of the American College of Cardiology Foundation/American Heart Association Task Force on practice guidelines. Circulation 2011;123:e269-367.

7. Cairns JA, Connolly S, McMurtry S; CCS Atrial Fibrillation Guidelines Committee. Canadian Cardiovascular Society Atrial Fibrillation Guidelines 2010: Prevention of Stroke and Systemic Thromboembolism in Atrial Fibrillation and Flutter. Can J Cardiol 2011;27:74-90.

8. You JJ, Singer DE, Howard PA, et al. Antithrombotic Therapy for Atrial Fibrillation: Antithrombotic therapy and Prevention of Thrombosis, $9^{\text {th }}$ ed: American College of Chest Physicians Evidence-Based Clinical Practice Guidelines. Chest 2012;141:e531S-75S.

9. Singer DE, Chang Y, Fang MC, et al. The clinical benefit of warfarin anticoagulation in atrial fibrillation. Ann Intern Med 2009;151:297-305.

10. Raviele A, Disertori M, Alboni P, et al. Linee guida AIAC 2010 per la gestione ed il trattamento della fibrillazione atriale. G Ital Aritm Clin 2010;13:62-157.

11. Hart RG, Pearce LA, Aguilare MI. Meta-analysis: antithrombotic therapy to prevent stroke in patients who have nonvalvular atrial fibrillation. Ann Intern Med 2007;146:857-67.

12. Connolly SJ, Ezekowitz MD, Yusuf S, et al. Dabigatran versus warfarin in patients with atrial fibrillation. N Eng J Med 2009; 361: 1139-51 e Connolly SJ, Ezekowitz MD, Yusuf S, Reilly PA, Wallentin L. Newly identified events in the RE-LY trial. N Eng J Med 2010;363:1875-6.

13. Patel MR, Mahaffey KW, Garg J, et al. Rivaroxaban versus warfarin in nonvalvular atrial fibrillation. N Engl J Med 2011;365:883-91.

14. Granger CB, Alexander JH, McMurray JJ, et al. Apixaban versus warfarin in patients with atrial fibrillation. $\mathrm{N}$ Engl J Med 2011;365:981-92.

15. Food and Drug Administration. FDA Drug Safety Communication: Safety review of post-market reports of serious bleeding events with the anticoagulant Pradaxa (dabigatran etexilate mesylate); 2011. Available from: http://www.fda.gov/Drugs/DrugSafety/ucm282724.htm

16. Diener HC, Connolly SJ, Ezekowitz MD et al. Dabigatran compared with warfarin in patients with atrial fibrillation and previous transient ischaemic attack or stroke: a subgroup analysis of the RE-LY trial. Lancet Neurol 2010;9:1157-63.

17. Hankey GJ, Patel MR, Stevens SR, et al. Rivaroxaban compared with warfarin in patients with atrial fibrillation and previous stroke or transient ischaemic attack: a subgroup analysis of ROCKET AF. Lancet Neurol 2012; 11:315-22.

18. Easton JD, Lopes RD, Bahit MC, et al. Apixaban com- 
pared with warfarin in patients with atrial fibrillation and previous stroke or transient ischaemic attack: a subgroup analysis of the ARISTOTLE trial. Lancet Neurol 2012;11:503-11.

19. Masotti L, Di Napoli M, Ageno W, et al. Efficacy and safety of new oral anticoagulants compared with warfarin in cardioembolic prophylaxis of patients with non valvular atrial fibrillation. More lights than shadows. Ital J Med 2012;6:153-69.

20. ACTIVE Investigators; Connolly SJ, Pogue J, et al. Effect of clopidogrel added to aspirin in patients with atrial fibrillation. N Engl J Med 2009;360:2066-78.

21. Connolly SJ, Eikelboom JW, Ng J, et al. Net clinical benefit of adding clopidogrel to aspirin therapy in patients with atrial fibrillation for whom vitamin $\mathrm{K}$ antagonists are unsuitable. Ann Intern Med 2011;155: 579-86.

22. Rasmussen LH, Larsen TB, Graungaard T, et al. Primary and secondary prevention with new oral anticoagulant drugs for stroke prevention in atrial fibrillation: indirect comparison analysis. BMJ 2012;345:e7097.

23. Diener HC, Eikelboom J, Connolly SJ, et al. Apixaban versus aspirin in patients with atrial fibrillation and previous stroke or transient ischaemic attack: a predefined subgroup analysis from AVERROES, a randomised trial. Lancet Neurol 2012;11:225-31.

24. SPREAD (Stroke prevention and educational awareness diffusion), Gensini GF, Zaninelli A, eds. Ictus cerebrale: Linee guida italiane di prevenzione e trattamento, 6th ed. Milan: Pierrel Research Italy SpA; 2010.

25. Alberts MJ, Bernstein RA, Naccarelli GV, Garcia DA. Using dabigatran in patients with stroke: a practical guide for clinicians. Stroke 2012;43:271-9.

26. Brouns R, Van Hooff RJ, De Smedt A, et al. Acute stroke management in patients taking dabigatran. CNS Neuros Ther 2012;18:616-22.

27. Huisman MV, Lip GYH, Diener HC, et al. Dabigatran etexilate for stroke prevention in patients with atrial fibrillation: resolving uncertainties in routine practice. Thromb Haemost 2012;107:838-47.

28. Turpie AGG, Kreutz R, Llau J, et al. Management consensus guidance for the use of rivaroxaban -an oral, direct factor Xa inhibitor. Thromb Haemost 2012;108: 876-86.

29. Palareti G, Ageno W, Ferrari A, et al. Clinical management of rivaroxaban-treated patients. Expert Opin Pharmacother 2013;14:655-67. 